\title{
GRAPHICAL-ANALYTICAL METHOD FOR CONSTRUCTING LOAD CHARACTERISTICS
}

\author{
${ }^{1} \mathrm{~A}$ N Rasulov, ${ }^{1} \mathrm{M}$ R Ruzinazarov, ${ }^{2} \mathrm{~A}$ S Muratov, ${ }^{3} \mathrm{M}$ R Chariyeva \\ ${ }^{1}$ Tashkent state technical university, Department of Power Supply, Tashkent. \\ ${ }^{2}$ Karakalpak State University, Nukus, Republic of Uzbekistan \\ ${ }^{3}$ Bukhara Engineering-Technological Institute, K.Murtazaev, St.15, Bukhara, 200117
}

\begin{abstract}
The article discusses a graphical-analytical method for constructing the load characteristics of a three-element resonant circuit in the current stabilization mode. The current stabilization mode is observed when compensating the negative section of the S-shaped characteristics of the parallel resonant circuit of the connected sequence with a linear inductance and with a linear capacitor characteristic. The equation of the load mode in a dimensionless form represents the equation of an ellipse, which makes it possible to construct the necessary characteristics of a three-element resonant circuit for various types of load.
\end{abstract}

\section{Introduction}

In engineering practice, various graphical methods for analyzing the operation of ferromagnetic devices have been applied. A graphical method is proposed for calculating the equivalent circuit of a three-element resonant circuit proposed in Fig. 1 in the current stabilization mode for a complex load [10-16].

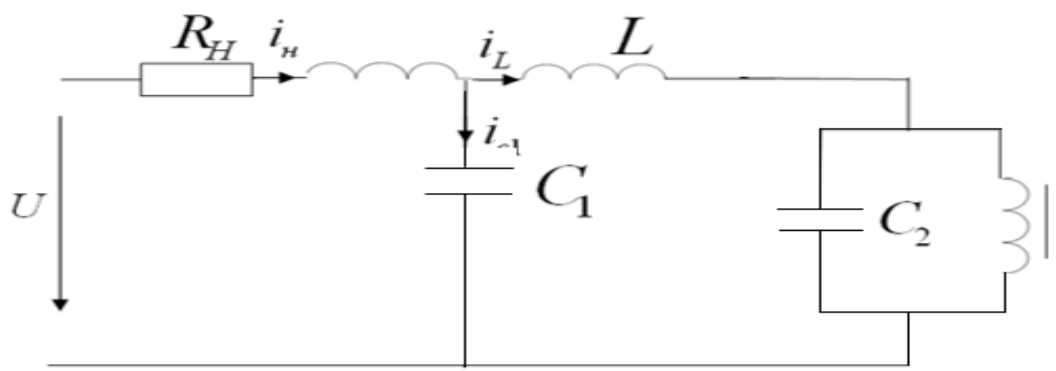

Fig. 1. Scheme of a ferroresonant current stabilizer.

In this case, the known current-voltage characteristic of the device for the unloaded mode and the currents of the branches of the circuit is assumed to be sinusoidal. [1-9] For the current stabilization mode with active-inductive load, the following equation is valid:

$$
u=L_{H} \frac{d i_{c}}{d t}+i_{c} R_{H}+u_{c}
$$

For active-capacitive load

$$
u=\frac{1}{c} \int i_{c} d t+i_{c} R_{H}+u_{c}
$$

here: $\mathrm{L}_{\mathrm{H}}, \mathrm{C}, \mathrm{R}_{\mathrm{c}}$, respectively, inductance, capacitance and active load resistance; $i_{c}$ - stabilization current;

$\mathrm{u}_{\mathrm{c}}$-voltage at the terminals of the three-element resonant circuit;

$\mathrm{u}$-mains voltage;

Accept $i_{c}=I_{c m} \sin \omega t, u_{c}=U_{c m} \cos \omega t ; \quad u=U_{m} \cos (\omega t+$ $\psi)$

Such an assumption is possible if the losses in the circuit of the circuit are neglected and provided that the circuit of the device operates in a capacitive mode. After some transformations and introduction of normalized values from (1) we get:

Where

$$
y_{m}^{2}=\left(\gamma Z_{m}-y_{\mathrm{c} m}\right)^{2}+\delta^{2} \beta_{1}^{2} Z_{m}^{2},
$$

$\gamma=\frac{L_{\mathrm{H}}}{L} ; \delta=\omega C_{1} R_{H} ; \beta_{1}=\frac{1}{\omega^{2} L C_{1}} ; \mathrm{y}_{\mathrm{cm}}=\frac{u_{c m}}{U_{\delta}} ; Z_{m}=\frac{I_{m}}{i_{\delta}} ; \mathrm{y}_{m}=\frac{u_{m}}{U_{\delta}}$. 
For the case of active-capacitive load

$$
\mathrm{y}_{m}^{2}=\left(\gamma_{\mathrm{c}} Z_{m}+\mathrm{y}_{c m}\right)^{2}+\delta^{2} \beta_{1} Z_{m}^{2}
$$

Here $\quad \gamma_{\mathrm{c}}=\frac{1}{\omega^{2} L \mathrm{C}_{\mathrm{H}}}$

From (3) and (5), respectively, for active-inductive and active-capacitive loads we get:

$$
\begin{aligned}
& \mathrm{y}_{m}^{2}=\left(\delta^{2} \beta_{1}^{2}+\gamma^{2}\right) Z_{m}+\mathrm{y}_{\mathrm{cm}}^{2}-2 \gamma Z_{m} \mathrm{y}_{c m}, \\
& \mathrm{y}_{m}^{2}=\left(\delta^{2} \beta_{1}^{2}+\gamma_{\mathrm{c}}{ }^{2}\right) Z_{m}^{2}+\mathrm{y}_{\mathrm{cm}}^{2}+2 \gamma_{\mathrm{c}} Z_{m} \mathrm{y}_{c m},
\end{aligned}
$$

These dependencies are equations of second order curves representing ellipses. We bring these equations to canonical form by rotating the coordinate axes through some angle $\alpha$. Old coordinates through new ones are determined by the following expressions: [17-24]

$$
\begin{aligned}
& Z_{m}=Z_{m}^{\prime} \cos \alpha-\mathrm{Y}_{c m}^{\prime} \sin \alpha \\
& \mathrm{y}_{m}=Z_{m}^{\prime} \sin \alpha-\mathrm{Y}_{c m}^{\prime} \cos \alpha
\end{aligned}
$$

Here $\alpha$ is the angle of rotation of the axes.

Substituting these values in (5), we have:

$$
A Z_{m}^{\prime 2}+2 B Z_{m}^{\prime} \mathrm{y}_{c m}^{\prime}+C \mathrm{y}_{c m}^{2}=0
$$

Where $A=\left(\delta^{2} \beta_{1}^{2}+\gamma^{2}\right) \cos ^{2} \alpha+\sin ^{2} \alpha-2 \gamma \sin \alpha \cos \alpha$,

$$
\begin{aligned}
& B=\left(\cos ^{2} \alpha+\sin ^{2} \alpha\right)-\left(\alpha^{2} \beta_{1}^{2}+\gamma-1\right) \sin \alpha \cos \alpha=0, \\
& C=\left(\delta^{2} \beta_{1}^{2}+\gamma^{2}\right) \sin ^{2} \alpha+\cos ^{2} \alpha+2 \gamma \sin \alpha \cos \alpha=0,
\end{aligned}
$$

The choice of the angle $\alpha$ is made in such a way that the coefficient B becomes zero. This will allow obtaining an expression for the angle of rotation $\gamma\left(\cos ^{2} \alpha-\sin ^{2} \alpha\right)$ $\left(\delta^{2} \beta_{1}^{2}+\gamma-1\right) \sin \alpha \cos \alpha=0$ [25-27],

From where $\operatorname{tg} 2 \alpha=-\frac{2 \gamma}{\delta^{2} \beta_{1}^{2}+\gamma-1}$

For active capacitive load $\operatorname{tg} 2 \alpha=\frac{2 \gamma_{\mathrm{c}}}{\delta^{2} \beta_{1}^{2}+\gamma_{\mathrm{c}}-1}$
Now we bring equation (7) to the form

$$
\begin{gathered}
A Z_{m}^{\prime 2}+C \mathrm{y}_{c m}^{\prime 2}=\mathrm{y}_{m}^{2} \text { Or } \\
\frac{Z_{m}^{\prime 2}}{\frac{\mathrm{y}_{m}^{2}}{A}}+\frac{\mathrm{y}_{c m}^{\prime 2}}{\frac{\mathrm{y}_{m}^{2}}{C}}=1
\end{gathered}
$$

Thus, the connection between $\mathrm{Z}_{\mathrm{m}}$ and $\mathrm{Y}_{\mathrm{cm}}$ for a fixed value of the load is determined by the equation of the ellipse (8) and the known current-voltage characteristic of the current stabilizer circuit. The graphical method allows you to visually analyze the load mode of the current stabilizer and build the necessary characteristics of the device. For the case of active load, the canonical form of the ellipse equation is as follows:

$$
\frac{z_{m}^{2}}{\frac{\mathrm{y}_{m}^{2}}{\delta^{2} \beta_{1}^{2}}}+\frac{\mathrm{y}_{c m}^{2}}{\mathrm{y}_{m}^{2}}=1
$$

Using the known values of the semiaxes $\frac{y_{m}}{\delta \beta}$ and $y_{m}$ plotted on the characteristics $\mathrm{Z}_{\mathrm{m}}=\mathrm{f}\left(\mathrm{y}_{\mathrm{cm}}\right)$ of the stabilizer of the ellipse. The intersection points define the corresponding values and $\mathrm{Z}_{\mathrm{m}}$ and $\mathrm{y}_{\mathrm{cm}}$. Figures 2 and 3 show a graphical method for determining the quantities of interest for the case of active, active-inductive and active-capacitive characteristics. The constructed adjustment and external characteristics according to the graphical method showed their identity with the characteristics constructed from the results of the analytical method [28-30].

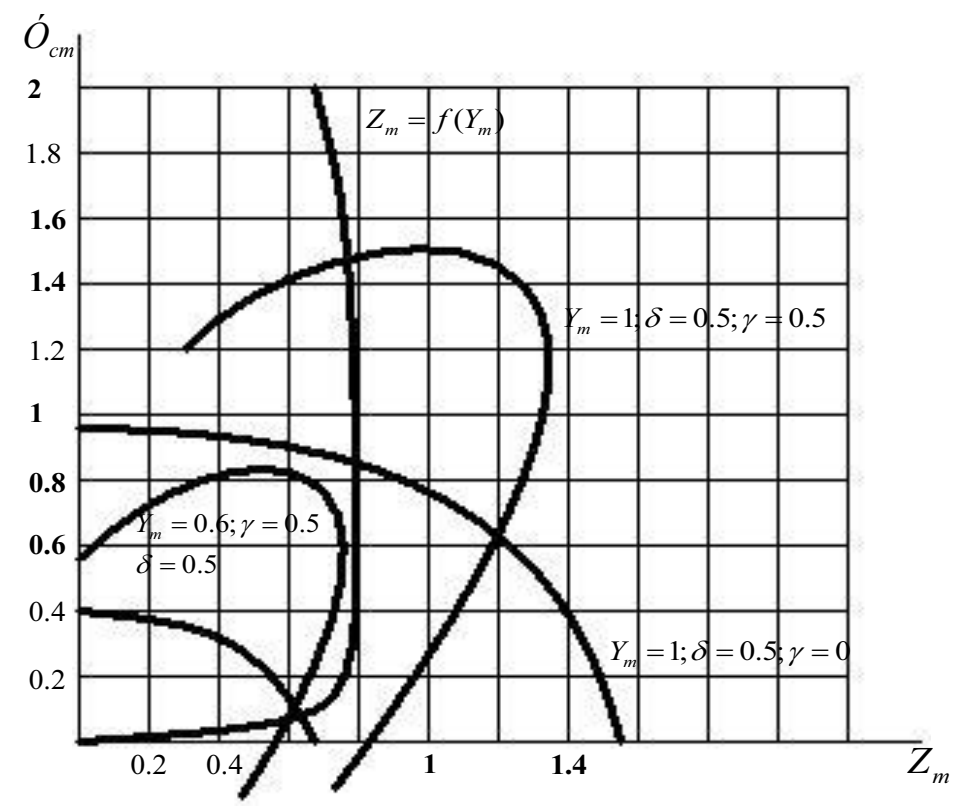

Fig. 2. Graphic method for determining $Z_{m}, U_{c m}$ 


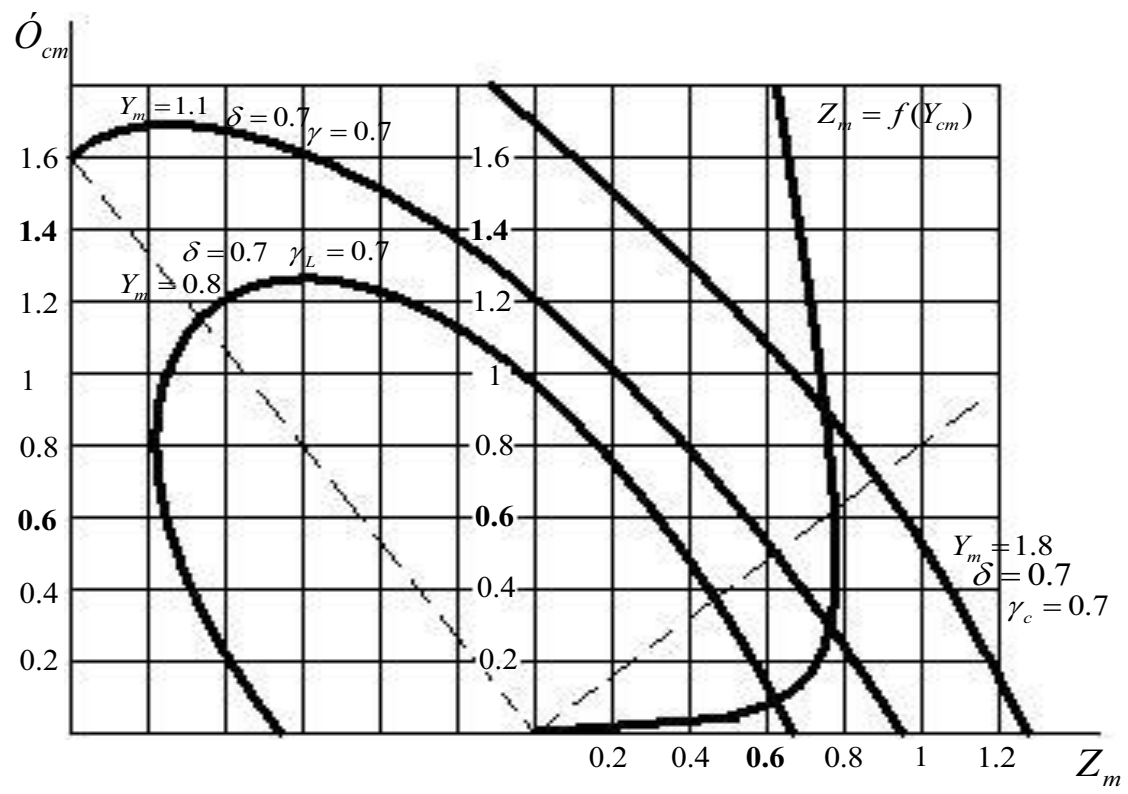

Fig. 3. Graphic method for determining $Z_{m}, y_{c m}$

\section{Conclusions}

1. Based on the analysis of the three-element resonant circuit, the possibilities of stabilizing the load current are revealed.

2. The relationship between the load current and the voltage of a parallel connected capacitor for a fixed load value is determined by the ellipse equation and the current-voltage characteristic of the current stabilizer circuit, which allows you to visually analyze the load mode and build the necessary characteristics.

\section{References}

1. Postnikov, V.I.,Ostapchuk, L.B. Asynchronous generators as power system's natural dampers. 43rd International Conference on Large High Voltage Electric Systems 2010, CIGRE 20102010, 9p43rd International Conference on Large High Voltage Electric Systems 2010, CIGRE 2010; Paris; France; 22 August 2010.

2. Fazylov, Kh.F.,Allaev, K.R. Analysis of the operation of an electrical system during simultaneous operation of synchronous and asynchronous generators. Power engineering New York Volume 18, Issue 3, 1980, Pages 81-88.

3.Fazylov, Kh.F.,Allaev, K.R. Asynchronous turbogenerators with stator excitation and the prospects for their utilization. Power engineering New York Volume 23, Issue 2, 1985, Pages 7-13.

4. Fazylov, Kh.F.,Allaev, K.R. Calculation and experimental analysis of conditions of electrical power systems containing induction generators Power Engineering New York Volume 27, Issue 6, 1989, Pages 27-34.

5. Taslimov, A.D., Rakhmonov, I.U. (2019) Optimization of complex parameters of urban distribution electric networks Journal of Physics: Conference Series 1399 doi:10.1088/17426596/1399/5/055046

6. Rakhmonov, I.U., Niyozov, N.N. (2019) Optimization setting of steel-smelting industry in the issue of alloy steels E3S Web Conf 139 doi:10.1051/e3sconf/201913901077

7. Rakhmonov, I.U., Reymov, K. M., Shayumova, Z.M. (2019) The role information in power management tasks. E3S Web Conf 139 doi:10.1051/e3sconf/201913901080

8. Rakhmonov, I.U., Reymov, K.M. (2019) Mathematical Models and Algorithms of Optimal Load Management of Electricity Consumers J ENERGETIKA. Proceedings of CIS higher education institutions and power engineering association 62(6) pp 528-535 doi:10.21122/1029-7448-2019-62-6-528-535

9. Rakhmonov, I. U., Tovbaev, A.N., Nematov, L.A., Alibekova,T.Sh. (2020) Development of forecasted values of specific norms for the issues of produced products in industrial enterprises Journal of Physics: Conference Series $\mathbf{1 5 1 5}$ doi:10.1088/17426596/1515/2/022050

10. Rakhmonov, I.U., Nematov, L.A., Niyozov, N.N, Reymov, K.M., Yuldoshev, T.M. (2020) Power consumption management from the positions of the general system theory Journal of Physics: Conference Series 1515 doi:10.1088/1742-6596/1515/2/022054

11. Rakhmonov, I.U., Reymov, K.M., Najimova, A.M., Uzakov, B.T., Seytmuratov, B.T. (2019) Analysis and calculation of optimum parameters of electric arc furnace Journal of Physics: Conference Series 1399 doi:10.1088/1742-6596/1399/5/055048

12. Rakhmonov, I.U., Reymov, K.M. (2019) Regularities of change of energy indicators of the basic technological equipment of the cotton-cleaning industry 
Journal of Physics: Conference Series 1399 doi:10.1088/1742-6596/1399/5/055038

13. Rakhmonov, I. U., Reymov, K.M., Dustova, S.H. (2020) Improvements in industrial energy rationing methods Journal of IOP: Conference Series. MIP: $\begin{array}{llll}\text { Engineering-2020. } & 862 & (2020) & 062070\end{array}$ doi:10.1088/1757-899X/862/2/062070

14. Rakhmonov, I.U., Berdishev, A.A., Niyozov, N.N., Muratov, A., Khaliknazarov U. (2020) Development of a scheme for generating the predicted value of specific electricity consumption Journal of IOP: Conference Series. MIP: Engineering-2020. 883 (2020) 012103 doi:10.1088/1757-899X/883/1/012103

15. Rakhmonov, I.U., Berdishev, A.A., Khusanov, B.M., Khaliknazarov, U., Utegenov, U. (2020) General characteristics of networks and features of electricity consumers in rural areas Journal of IOP: Conference Series. MIP: Engineering-2020. 883 (2020) 012104 doi:10.1088/1757-899X/883/1/012104

16. Hoshimov, F.A., Bakhadirov, I.I., Erejepov, M., Djumamuratov, B. (2019) Development of method for normalizing electricity consumption E3S Web Conf 139 doi:10.1051/e3sconf/201913901074

17. Karimov R.Ch., Bobojanov M.K., Rasulov A.N., Usmanov E.G. E3S Web of Conferences, 139, 01039, (2019), doi.org/10.1051/e3sconf/201913901039;

18. Karimov R.Ch., Shamsiyev K., and others. IOP Conf. Series: Materials Science and Engineering, 883(1), 012142, (2020). doi:10.1088/1757-899X/883/1/012142;

19. E.G.Usmanov, A.N.Rasulov, M.K.Bobojanov, R.Ch.Karimov. E3S Web of Conferences 139, 01079 (2019), doi.org/10.1051/e3sconf/201913901079;

20. Karimov R.Ch., Shamsiyeva N. and others. IOP Conf. Series: Materials Science and Engineering, 883(1), 012120, (2020). doi:10.1088/1757-899X/883/1/012120

21. G.R.Rafikova, M.R.Ruzinazarov, S.K.Makhmutkhonov. E3S Web of Conferences, 139, 01075,

(2019), https://doi.org/10.1051/e3sconf/201913901075

22. Khakimov,H.T., Shayumova,Z.M., Kurbanbaeva,Z. K., Khusanov,B.M. Development of optimal modes and mathematical models of energy performance of electric steelmaking production//E3S Web of Conferences, 2019, 139, 01076

23. Toshov, Zh.B. Ways towards optimization of washout components of rock cutting tools Information about author // Gornyi Zhurnal. Volume 2016, Issue 2, 1 January 2016, Pages 21-24.

24. Burievich, T.J. The questions of the dynamics of drilling bit on the surface of well bottom// Arch. Min. Sci. -Poland. - Vol. 61 (2016). - №2. - P. 279-287. DOI 10.1515/amsc-2016-0020.

25. Toshniyozov, L.G., Toshov, J.B. Theoretical and experimental research into process of packing in drilling// Mining Informational and Analytical Bulletin Volume 2019, Issue 11, 2019, Pages
139-151. DOI: 10.25018/0236-1493-2019-11-0-139151.

26. Avezova N.R., Toshov J.B., Dalmuradova N.N., Farmonova A.A., Mardonova M.Sh.Renewable Energy: Scenario and Model of Development // ISSN 0003-701X, Applied Solar Energy, 2019, Vol. 55, No. 6, pp. 438-445. DOI: 10.3103/S0003701X19060021

27. Azamatovich, A.N., Amrillo, M.B, Burievich, T.J., Umarxanoxich, J.R., Shavkatovich, Z.A. A complex of methods for analyzing the working fluid of a hydrostatic power plant for hydraulic mining machines / International Journal of Advanced Science and Technology. Volume 29, Issue 5 Special Issue, 28 March 2020, Pages 852-855

28. Karimov R.Ch., Shamsiyev K., and others. IOP Conf. Series: Materials Science and Engineering, 883(1), 012142, (2020). doi:10.1088/1757-899X/883/1/012142 29. Karimov R.Ch., Shamsiyeva N. and others. IOP Conf. Series: Materials Science and Engineering, 883(1), 012120, (2020). doi:10.1088/1757-899X/883/1/012120

30. E.G.Usmanov, A.N.Rasulov, M.K.Bobojanov, R.Ch.Karimov. E3S Web of Conferences 139, 01079 (2019), doi.org/10.1051/e3sconf/201913901079 